\title{
Birth weight and cardiovascular risk factors in an epidemiological study
}

\author{
E. Vestbo ${ }^{1}$, E. M. D amsgaard ${ }^{2}$, A . Frøland ${ }^{3}$, C. E . M ogensen ${ }^{1}$ \\ ${ }^{1}$ M edical D epartment M (D iabetes and E ndocrinology), A arhus Kommunehospital, A arhus, D enmark \\ ${ }^{2} \mathrm{G}$ eriatric D epartment $C$, M arselisborg H ospital, A arhus, D enmark \\ ${ }^{3}$ M edical D epartment, Fredericia H ospital, Fredericia, D enmark
}

Summary Low birth weight has been proposed as a risk factor for development of non-insulin-dependent diabetes mellitus, hypertension, and cardiovascular disease in the adult. To ascertain the extent to which birth weight was associated with cardiovascular risk factors, we examined 620 subjects (median age 48 years) in a cross-sectional study. Of these 317 were offspring of diabetic patients and 303 were offspring of non-diabetic control subjects. K nown risk factors for development of cardiovascular disease were correlated to birth weight and examined as dependent variables by multiple linear regression. A ge, body mass index (BMI), subjects gender along with parental gender, diabetes status of the parents, and birth weight were independent variables. The variance of the risk factors as dependent variables explained by age, gender, and B M I as independent variables was examined and birth weight was added as an independent variable. We found birth weight was inconsistently correlated to the different risk factors in the different groups of subjects. When adjusted for age, BMI, subject's gender, parental gender, and the diabetes status of the parents, birth weight was negatively correlated to fasting blood glucose. In offspring of diabetic patients the explained variance of risk factors did not change as we added birth weight to the model. In offspring of non-diabetic subjects we found that the explained variance of diastolic blood pressure, fasting blood glucose, $\mathrm{HbA}_{\mathrm{IC}}$, and cholesterol increased $1-3 \%$ as birth weight was added to the model. We conclude that birth weight may not be a major risk factor for development of hypertension and cardiovascular disease in our population. [D iabetologia (1996) 39: 1598-1602]

Keywords Birth weight, cardiovascular disease, hypertension, non-insulin-dependent diabetes mellitus, obesity.
R etarded fetal growth has been proposed as a risk factor for development of insulin resistance [1], impaired beta-cell function [2], and impaired glucose tolerance [3-5]. These studies show a negative linear relation to birth weight. In Pima Indians, a population with very high prevalence of non-insulin-dependent diabetes mellitus (NIDDM ) a U -shaped relation between the prevalence of NIDDM and birth weight has been shown [6]. A $n$ inverse correlation has been found between birth weight and blood pressure in adults [7] and the risk of hypertension in adults has been shown

Corresponding author: D r. E . Vestbo, M edical D epartment M, A arhus K ommunehospital, D K -8000 A arhus C, D enmark A bbreviations: IDDM, Insulin-dependent diabetes mellitus; NID D M , non-insulin-dependent diabetes mellitus. to increase in subjects with low birth weight but from a large placenta [8]. E ven increased risk of cardiovascular disease in adult life [9] and increased risk of death from ischaemic heart disease [10] have been found in subjects with low birth weight.

To study the possible associations between birth weight and known risk factors for development of cardiovascular disease we examined 620 subjects in a cross-sectional study. Of these 317 subjects had a family history of diabetes and 303 were offspring of non-diabetic control subjects. O ur purpose was to examine whether birth weight was related to known risk factors for the development of diabetes and cardiovascular risk factors. We also examined to what degree birth weight contributed to the so-far explained variance of different risk factors for the 
Table 1. Clinical data of the study population

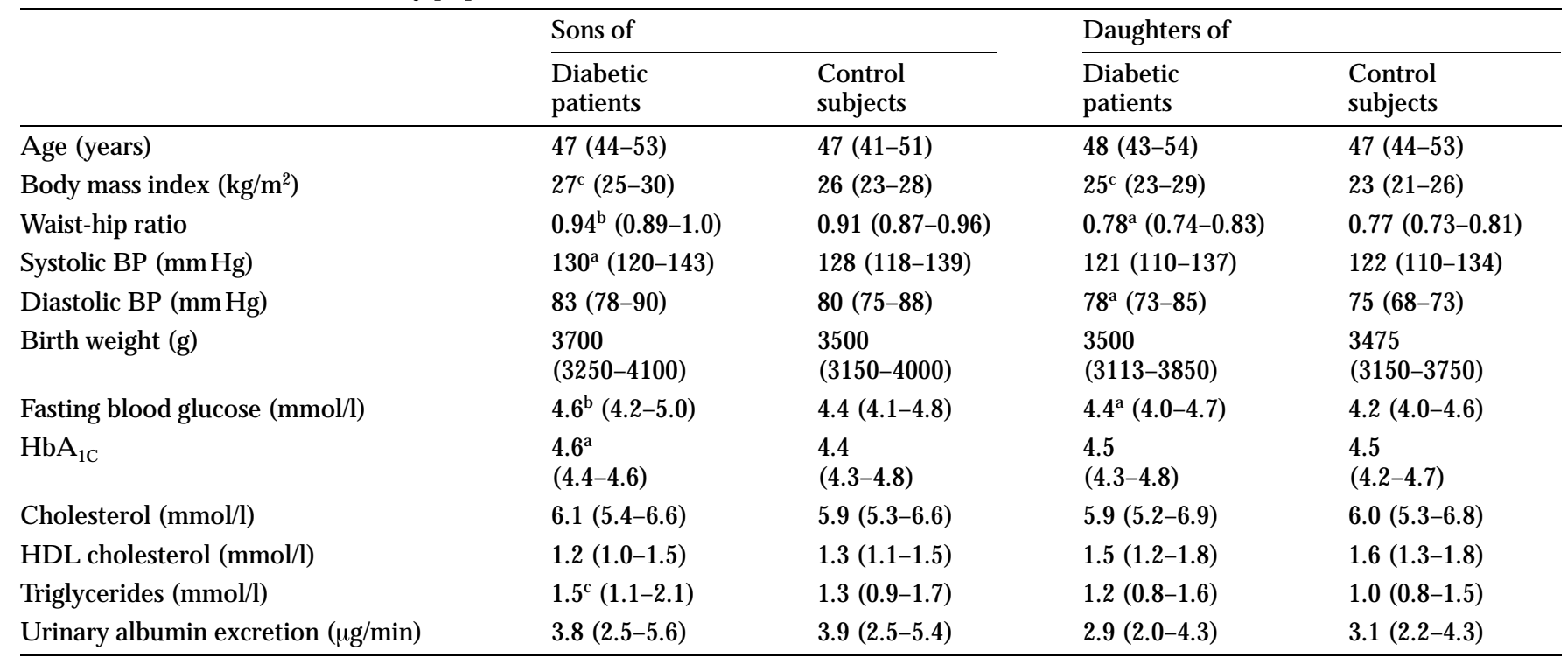

M edian values, 25 and 75 percentiles shown. SB P, Systolic blood pressure; D B P, diastolic blood pressure;

${ }^{a} p<0.05 ;{ }^{b} p<0.01$ and ${ }^{c} p<0.001$ compared to control subjects

Table 2. Correlation between birth weight and different risk factors for development of cardiovascular disease

\begin{tabular}{|c|c|c|c|c|}
\hline & \multicolumn{2}{|l|}{ Sons of } & \multicolumn{2}{|c|}{ D aughters of } \\
\hline & $\begin{array}{l}\text { Diabetic } \\
\text { patients }\end{array}$ & $\begin{array}{l}\text { Control } \\
\text { subjects }\end{array}$ & $\begin{array}{l}\text { Diabetic } \\
\text { patients }\end{array}$ & $\begin{array}{l}\text { Control } \\
\text { subjects }\end{array}$ \\
\hline B ody mass index & 0.12 & 0.14 & 0.13 & -0.001 \\
\hline Waist-hip ratio & $0.23^{b}$ & -0.07 & 0.08 & -0.04 \\
\hline Systolic BP & -0.02 & -0.06 & 0.07 & -0.06 \\
\hline D iastolic BP & -0.01 & -0.08 & 0.07 & -0.07 \\
\hline Fasting blood glucose & -0.02 & $-0.20^{b}$ & 0.05 & -0.02 \\
\hline $\mathrm{HbA}_{1 \mathrm{c}}$ & -0.05 & -0.03 & 0.11 & $0.23^{b}$ \\
\hline Cholesterol & $0.17^{a}$ & $-0.20^{a}$ & 0.05 & -0.03 \\
\hline HDL cholesterol & -0.01 & -0.11 & -0.05 & 0.02 \\
\hline Triglycerides & 0.11 & -0.02 & -0.02 & -0.03 \\
\hline $\begin{array}{l}\text { U rinary al bumin } \\
\text { excretion }\end{array}$ & 0.01 & 0.10 & -0.09 & -0.01 \\
\hline
\end{tabular}

SBP, Systolic blood pressure; D BP, diastolic blood pressure; the correlation coefficients are shown

${ }^{a} p<0.05 ;{ }^{b} p<0.01$

development of cardiovascular disease in the two populations, when adjusted for relevant confounders.

\section{Subjects and methods}

Subjects. In 1981-1982, 228 subjects with known diabetes (20 insulin-dependent [IDDM ] and 208 NIDDM) and a control group of 221 subjects, were examined. A II subjects were recruited from a population-based survey of $93 \%$ of all subjects aged 60-74 years living in the community of Fredericia, $D$ enmark [11]. These subjects gave the names and birth dates of their children. The probands had 1029 children. In 19911992 we located 1002 of these subjects of which 110 had died before this study, and 43 were living abroad during the period of examination. Of 849 subjects invited to undergo a clinical and laboratory examination 740 (87\%) accepted. We found that 39 subjects had diabetes and 4 had non-diabetic kidney disease with proteinuria, the remaining 697 non-diabetic children had no kidney disease. Thirty-nine of the children of known diabetic subjects were offspring of IDDM patients, exclusion of these did not change the results which is why they are included in the analysis.

$D$ ata on birth weight from midwives' records were available for 620 subjects of this group. The subjects were born at home, midwives were called to the homes and after the birth they recorded information on the mother, father, pregnancy, birth, weight, length, and the health of the child. Midwives are required by law to compile these records, which are kept in an archive. O nly one record was made per child. A s the subjects generally had no knowledge of their own birth weight, it was not possible to examine the validity of these data.

$\mathrm{H}$ eight and weight were measured without shoes or outdoor clothing, and body mass index (BMI) was calculated as weight $(1 \mathrm{~kg})$ divided by height $\left(\mathrm{m}^{2}\right)$. Waist circumference was measured at the level of the umbilicus and hip circumference was measured at the level of the greater trochanter. Waist/hip ratio was calculated. Systolic (first phase) and diastolic (fifth phase) blood pressure was recorded using a random-zero sphygmomanometer ( $\mathrm{H}$ awksley-G elman, L ondon, U K). Two readings were recorded for each individual, and the average was defined as the subject's blood pressure.

Fasting blood glucose was measured with glucose dehydrogenase (M erck, CO BA S M IR A, H vidovre, D enmark) haemoglobin was measured by $C$ yan hemiglomen on a Coulter J $S$, (A lbertslund, Denmark) sodium and potassium were measured by ion selective electrode (HITA CHI 717, K vistgaard, D enmark), serum creatinine was measured by the Jaffe reaction. C-peptide was measured by RIA-kit with antibody M 1221 from N ovo R esearch Institute (B agsvaerd, D enmark), and $\mathrm{HbA}_{1 \mathrm{c}}$ was measured by a liquid-chromatographic assay [12]. Fasting insulin was measured by Wick chromatography for immunoassay of insulin [13]. Cholesterol was measured by the CHOD -PA P method (Boehringer M annheim, M annheim, Germany). 
Offspring of NIDDM patients
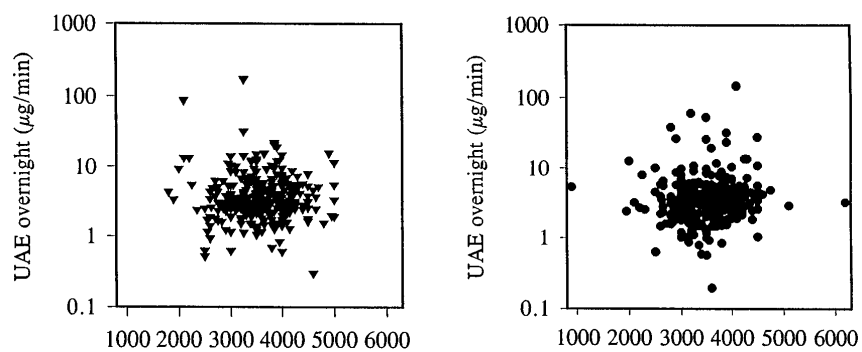

Birth weight (g)

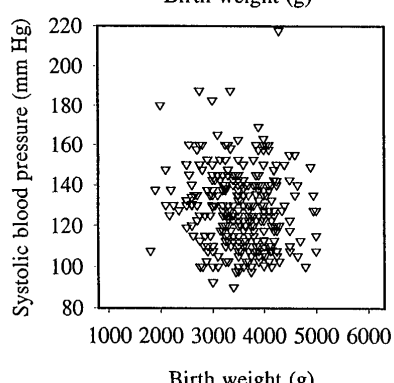

Birth weight $(\mathrm{g})$
Offspring of control subjects

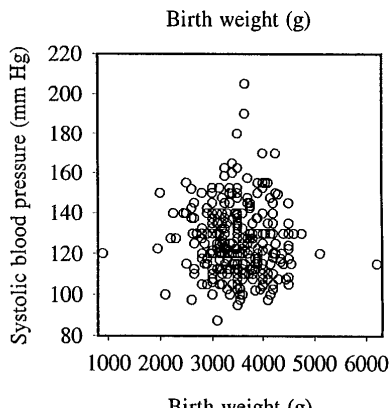

Fig. 1. R elation between birth weight and urinary albumin excretion rate (UAE) and birth weight and systolic blood pressure in offspring of NIDDM patients and in offspring of nondiabetic control subjects

Two timed overnight urine specimens were obtained. A lbumin concentration was measured by polyethyleneglycol radioimmunoassay [14] and urinary albumin excretion rate was calculated. The geometric mean of the two collections was used.

\section{Statistical analysis}

U rinary albumin excretion rate did not follow normal distribution and was log transformed. Correlation coefficients were calculated by Pearson's correlation.

Multiple linear regression was used, with cardiovascular risk factors as dependent variables and age, gender, body mass index, and birth weight in the second generation along with dummy variables for parental gender and the NIDDM status of the parents as independent variables. G ender was noted as: $1=$ male, $0=$ female; NIDDM status of the parent was noted as: $1=$ NIDDM in parent, $0=$ non-NIDDM in parent. Furthermore, multiple linear regression with risk factors as dependent variables and age, gender, and body mass index in the second generation with and without birth weight as independent variables was analysed. The change in $R^{2}$ (explained variance) for these models was noted. The statistical package SPSS

for windows, (SPSS software; Chicago, III., U SA ) was used for calculations.

\section{Results}

The clinical data is shown in Table 1. The median and 25- 75 percentiles are shown. $O$ ffspring of diabetic patients, males as well as females had higher BMI, waist-hip ratio and fasting blood glucose levels compared to offspring of non-diabetic control subjects. We found no significant difference in birth weight between sons of diabetic patients and sons of control subjects or between female offspring of the two groups.

The correlations between birth weight and the different risk factors are shown in Table 2. A s shown, there was an inconsistent correlation between birth weight and the different risk factors in the different groups of subjects. We found no correlation between either birth weight and blood pressure, or between birth weight and urinary albumin excretion rate (Fig. 1).

Tables 3 and 4 show the results of the multiple linear regression of the different risk factors as dependent variables and age, gender, B M I, and birth weight in the second generation as independent variables along with parental gender and NIDDM status of the parent. In this model birth weight seemed to be negatively related to some risk factors, but the relation was only significant in fasting blood glucose.

Table 5 shows the variance of systolic and diastolic blood pressure, fasting blood glucose, $\mathrm{H} \mathrm{bA}_{1 \mathrm{c}}$, cholesterol and urinary albumin excretion explained by a multiple linear regression model with age, sex and BMI as independent variables. Furthermore, birth weight was added to the multiple linear regression to analyse whether the explained variance changed significantly. In offspring of diabetic patients we did not find changes in any of the explained variance of the risk factors. In offspring of control subjects we found that the explained variance of diastolic blood pressure, fasting blood glucose, $\mathrm{HbA}_{1 \mathrm{c}}$ and cholesterol increased as we added birth weight to the model. In all cases the coefficients of the relation between the different risk factors and birth weight were negative.

Table 3. M ultiple linear regression of cardiovascular risk factors as dependent variables. A ge, BM I, gender, gender of the parent, NID D M status of the parent, and birth weight as independent variables

\begin{tabular}{|c|c|c|c|c|c|c|c|c|c|}
\hline \multirow{2}{*}{$\begin{array}{l}\text { Independent } \\
\text { variables }\end{array}$} & \multicolumn{3}{|c|}{ Systolic blood pressure } & \multicolumn{3}{|c|}{ D iastolic blood pressure } & \multicolumn{3}{|c|}{ Fasting blood glucose } \\
\hline & $\bar{B}$ & SE (B) & $\overline{p \text { value }}$ & $\bar{B}$ & SE (B) & $\mathrm{p}$ & $\bar{B}$ & SE (B) & $p$ \\
\hline A ge & 0.61 & 0.09 & $<0.001$ & 0.21 & 0.05 & 0.001 & 0.008 & 0.003 & 0.01 \\
\hline Gender & -5.39 & 1.25 & $<0.001$ & -4.22 & 0.75 & $<0.001$ & -0.14 & 0.05 & 0.002 \\
\hline Parental gender & 0.37 & 1.30 & 0.78 & -0.09 & 0.78 & 0.91 & -0.07 & 0.05 & 0.16 \\
\hline Parent NID DM & -0.38 & 1.26 & 0.76 & 0.25 & 0.75 & 0.74 & 0.09 & 0.05 & 0.04 \\
\hline Birth weight & -0.002 & 0.001 & 0.08 & -0.001 & 0.0006 & 0.05 & -0.0001 & 0.00003 & 0.008 \\
\hline
\end{tabular}


Table 4. M ultiple linear regression of cardiovascular risk factors as dependent variables. A ge, B M I, gender, gender of the parent, NID D M status of the parent, and birth weight as independent variables

\begin{tabular}{|c|c|c|c|c|c|c|c|c|c|}
\hline \multirow{2}{*}{$\begin{array}{l}\text { Independent } \\
\text { variables }\end{array}$} & \multicolumn{3}{|l|}{$\mathrm{HbA}_{1 \mathrm{c}}$} & \multicolumn{3}{|l|}{ Cholesterol } & \multicolumn{3}{|c|}{ Ln U rinary al bumin excretion } \\
\hline & $B$ & SE (B) & $p$ & $B$ & SE (B) & $p$ & $B$ & SE (B) & $p$ \\
\hline $\begin{array}{l}\text { A ge } \\
\text { B ody mass index } \\
\text { Gender } \\
\text { Parental gender } \\
\text { Parent NIDD M } \\
\text { B irth weight }\end{array}$ & $\begin{array}{l}1.2\left(10^{-4}\right) \\
1.0\left(10^{-4}\right) \\
-4.0\left(10^{-4}\right) \\
-2.6\left(10^{-4}\right) \\
7.8\left(10^{-4}\right) \\
-4.5\left(10^{-7}\right)\end{array}$ & $\begin{array}{l}2.1\left(10^{-5}\right) \\
3.2\left(10^{-5}\right) \\
3.0\left(10^{-4}\right) \\
3.1\left(10^{-4}\right) \\
3.0\left(10^{-4}\right) \\
2.6\left(10^{-7}\right)\end{array}$ & $\begin{array}{l}<0.001 \\
0.002 \\
0.18 \\
0.41 \\
0.01 \\
0.08\end{array}$ & $\begin{array}{l}0.03 \\
0.02 \\
0.10 \\
-0.11 \\
0.01 \\
-5.2\left(10^{-5}\right)\end{array}$ & $\begin{array}{l}0.007 \\
0.01 \\
0.10 \\
0.10 \\
0.10 \\
8.1\left(10^{-5}\right)\end{array}$ & $\begin{array}{l}<0.001 \\
0.02 \\
0.28 \\
0.28 \\
0.90 \\
0.52\end{array}$ & $\begin{array}{l}1.7\left(10^{-4}\right) \\
0.03 \\
-0.21 \\
-0.17 \\
-0.04 \\
-1.9\left(10^{-5}\right)\end{array}$ & $\begin{array}{l}0.004 \\
0.007 \\
0.06 \\
0.06 \\
0.06 \\
5.1\left(10^{-5}\right)\end{array}$ & $\begin{array}{l}0.97 \\
<0.001 \\
<0.001 \\
0.009 \\
0.46 \\
0.72\end{array}$ \\
\hline
\end{tabular}

Table 5. The variance of systolic and diastolic blood pressure $(\mathrm{BP})$, fasting blood glucose, $\mathrm{H} \mathrm{bA}_{1 \mathrm{c}}$, cholesterol and urinary albumin excretion rate explained by age, B MI and sex by multiple linear regression and age, BMI, sex and birth weight in a further multiple linear regression

\begin{tabular}{|c|c|c|c|c|}
\hline \multirow[t]{2}{*}{$\begin{array}{l}\text { Independent } \\
\text { variable }\end{array}$} & \multicolumn{2}{|c|}{$\begin{array}{l}\text { O ffspring of } \\
\text { diabetic patient }\end{array}$} & \multicolumn{2}{|c|}{$\begin{array}{l}\text { Offspring of } \\
\text { control subject }\end{array}$} \\
\hline & $\begin{array}{l}\text { A ge, } \\
\text { BMI, } \\
\text { Sex }\end{array}$ & $\begin{array}{l}\text { A ge, BMI, } \\
\text { Sex, birth } \\
\text { weight }\end{array}$ & $\begin{array}{l}\text { A ge, } \\
\text { BMI, } \\
\text { Sex }\end{array}$ & $\begin{array}{l}\text { A ge, BM I, } \\
\text { Sex, birth } \\
\text { weight }\end{array}$ \\
\hline Systolic BP & 26 & 26 & 25 & 26 \\
\hline D iastolic BP & 21 & 21 & 26 & $27^{a}$ \\
\hline $\begin{array}{l}\text { Fasting blood } \\
\text { glucose }\end{array}$ & 16 & 16 & 10 & $13^{b}$ \\
\hline $\mathrm{HbA}_{1 \mathrm{c}}$ & 9 & 9 & 9 & $10^{a}$ \\
\hline Cholesterol & 7 & 7 & 7 & $9^{a}$ \\
\hline $\begin{array}{l}\text { U rinary al bumin } \\
\text { excretion }\end{array}$ & 7 & 7 & 4 & 4 \\
\hline
\end{tabular}

${ }^{a} p<0.05 ;{ }^{b} p<0.01$

Values given as percent $(\%)$

\section{Discussion}

In general we found an inconsistent association between birth weight and cardiovascular risk factors. $B$ irth weight was, however, inversely correlated to fasting blood glucose when adjusted for age, BMI, and gender in the second generation, parental gender, and NIDDM status of the parent. This indicates that subjects with low birth weight have higher fasting blood glucose than subjects with high birth weight. This may support the results of impaired glucose metabolism in subjects with low birth weight [2-5] or insulin resistance in adults who had a low birth weight [1], as high fasting blood glucose may indicate impaired glucose metabolism. Low ponderal index (birth weight/height ${ }^{3}$ ) has been shown to increase the risk of diabetes in elderly men [15]. We did not test glucose intolerance in this study.

$B$ irth weight tended to be inversely correlated to blood pressure in the overall multiple linear regression, however it did not reach significance. By dividing the population into offspring of diabetic and non-diabetic subjects, birth weight in offspring of non-diabetic subjects was inversely correlated to diastolic blood pressure and cholesterol, when adjusted for age, B M I and gender. The inverse correlation to diastolic blood pressure $(p=0.05)$ may support the results of increased risk of hypertension [7, 8] and cardiovascular disease [10] found in previous studies. Brenner et al. [16, 17] have hypothesised that low birth weight infants have reduced numbers of glomeruli, resulting in increased risk of hypertension. Leon et al. [18] found that obese men with low birth weight had higher blood pressure than obese men with high birth weight. We found no correlation to urinary albumin excretion rate. In this study the change in explained variance caused by the addition of birth weight was very small, and found only in the subjects without family history of diabetes. To our knowledge no other study has attempted to describe the proportion of variance of different risk factors explained by birth weight when adjusted for relevant confounders. U sing disproportionate fetal growth as ponderal index (birth weight/length ${ }^{3}$ ) in the analysis rather than birth weight did not change the results.

$D$ iabetes in the probandswas diagnosed years after the birth of this second generation, except for a few of the parents with ID D M , and excluding their offspring did not change our results. In Pima Indians, M cCance et al. [6] found that the prevalence of NIDDM was greatest in subjects with the lowest and the highest birth weights. A s Pima I ndians as a group have a very high prevalence of NIDDM they are all more or less predisposed to NIDDM and therefore we could compare the Pimas to our population of offspring of diabetic patients. We found no $U$-shaped relations between birth weight and risk factors. The proband generation in our study was not examined for gestational diabetes. Diabetes and cardiovascular risk factors have been shown to be closely related [19-21] and probands who might have gestational diabetes might give birth to children with higher birth weight.

In our study we found no significant relation between birth weight and urinary albumin excretion rate. A s urinary albumin excretion is a marker related to hypertension and a predictor of cardiovascular disease in diabetic patients [22] as well as non-diabetic subjects $[23,24]$ one might have expected increased urinary albumin excretion in subjects with low birth weight. Short stature has been reported to 
be associated with high urinary albumin excretion rate in non-diabetic males, G ould et al. [25] and R ossing et al. [26] showed that the risk of nephropathy in IDDM males decreased with increasing height, but this was not the case in females. In a recent study Eshøj et al. [27] found that low birth weight was not associated with diabetic nephropathy in IDDM patients.

In our environment low birth weight may not be attributed to nutritional deficiencies in utero. As birth weight only contributes very little to the explained variance of the different cardiovascular risk factors, this study does not support the hypothesis that low birth weight is a major risk factor for development of hypertension and cardiovascular disease. We suggest that the effort in preventing these diseases must be focused on other risk factors. In this study obesity seemed to be a more relevant factor as well as aging. However, this paper was based on a cross-sectional study; follow-up studies are required to determine the importance of low birth weight in the development of diabetes, and death from cardiovascular disease.

\section{References}

1. Phillips DIW, Barker DJP, Hales CN, Hirst S, O smond C (1994) Thinness at birth and insulin resistance in adult life. D iabetologia 37: 150-154

2. Cook JT, Levy JC, Page RC, Shaw JA, H attersley AT, Turner RC (1993) A ssociation of low birth weight with beta cell function in the adult first degree relatives of noninsulin dependent diabetic subjects. B M J 306: 302-306

3. Hales CN, Barker DJ, Clark PM et al. (1991) Fetal and infant growth and impaired glucose tolerance at age 64 . B MJ 303: 1019-1022

4. Robinson S, Walton RJ, Clark PM, Barker DJ, Hales CN, O smond C (1992) The relation of fetal growth to plasma glucose in young men. D iabetologia 35: 444-446

5. Phipps K, Barker DJP, Hales CN, Fall CHD, O smond C, Clark PM S (1993) Fetal growth and impaired glucose tolerance in men and women. D iabetologia 36: 225-228

6. McCance DR, Pettitt DJ, Hanson RL, Jacobsson $L T$, K nowler WC, B ennett PH (1994) Birth weight and non-insulin dependent diabetes: thrifty genotype, thrifty phenotype, or surviving small baby genotype? BM J 308: 942-945

7. Holland FJ, Stark O, A des A E, Peckham CS (1993) Birth weight and body mass index in childhood, adolescence, and adulthood as predictors of blood pressure at age 36 . J E pidemiol Community $\mathrm{H}$ ealth 47: 432-435

8. B arker DJ, B ull A R, O smond C, Simmonds SJ (1990) Fetal and placental size and risk of hypertension in adult life. B MJ 301: 259-262

9. B arker D J, G luckman PD, G odfrey K M , H arding J E , O wens JA, R obinson J S (1993) F etal nutrition and cardiovascular disease in adult life. L ancet 341: 938-941
10. B arker DJ, Winter PD, $O$ smond C, M argetts $B$, Simmonds SJ (1989) Weight in infancy and death from ischaemic heart disease. L ancet 2: 577-580

11. Damsgaard E M, Faber O K, Frøland A et al. (1987) Prevalence of fasting hyperglycemia and known non-insulin-dependent diabetes mellitus classified by plasma C-peptide: Fredericia survey of subjects $60-74 \mathrm{yr}$ old. D iabetes $C$ are 10: 26-32

12. J eppsson J $O$, J erntorp P, Sundkvist $G$, Englund $H$, N ylund $V$ (1986) Measurement of hemoglobin A lc by a new liquid-chromatographic assay: methodology, clinical utility, and relation to glucose tolerance evaluated. Clin Chem 32: 1867-1872

13. Ørskov H , Thomsen G H , Y de H (1968) Wick chromatography for rapid and reliable immunoassay of insulin, glucagon and growth hormone. Nature 219: 193-195

14. Christensen CK, Ø rskov C (1984) R apid screening PE G radioimmunoassay for quantification of pathological microalbuminuria. Diabetic N ephropathy 3: 92-94

15. Lithell H O, M cK eigue PM , B erglund L, M ohsen R, L ithell U B, L eon DA (1996) R elation of size at birth to non-insulin dependent diabetes and insulin concentrations in men aged 50-60 years. B MJ 312: 406-410

16. B renner B M , Chertow G M (1994) Congenital oligonephropathy and the etiology of adult hypertension and progressive renal injury. A m J K idney $D$ is 23: 171-175

17. B renner BM, Garcia DL, A nderson S (1988) Glomeruli and blood pressure. Less of one, more the other? A $\mathrm{m} \mathrm{J} \mathrm{H} \mathrm{y-}$ pertens 1: 335-347

18. L eon DA, Koupilova I, Lithell $\mathrm{HO}$ et al. (1996) Failure to realise growth in utero and adult obesity in relation to blood pressure in 50 year old Swedish men. B MJ 312: 401406

19. K annel W B, M CG ee D L (1979) Diabetes and cardiovascular disease. The Framingham study. JA M A 241: 2035-2038

20. $\mathrm{H}$ affner SM , Stern M P, H azuda H P, M itchell B D, Patterson JK (1990) Cardiovascular risk factors in confirmed prediabetic individuals. $D$ oes the clock for coronary heart disease start ticking before the onset of clinical diabetes? JA M A 263: 2893-2898

21. H affner SM, Stern M P, H azuda H P, M itchell B D, Patterson J K , Ferrannini E (1989) Parental history of diabetes is associated with increased cardiovascular risk factors. A rteriosclerosis 9: 928-933

22. Schmitz A , Vaeth M (1988) M icroalbuminuria: a major risk factor in non-insulin-dependent diabetes. A 10-year followup study of 503 patients. Diabet M ed 5: 126-134

23. Y udkin J S, Forrest R D, Jackson CA (1988) M icroalbuminuria as a predictor of vascular disease in non-diabetic subjects. L ancet II : 530-533

24. D amsgaard E M , Frøland A, J ørgensen OD, M ogensen CE (1990) M icroalbuminuria as a predictor of increased mortality in elderly people. B M J 300: 297-300

25. Gould MM, Mohamed A li V, Goubet SA, Yudkin JS, Haines A P (1993) Microalbuminuria: associations with height and sex in non-diabetic subjects. B MJ 306: 240-242

26. R ossing P, Tarnow L, N ielsen FS, B oelskifte S, B renner B N, Parving H H (1995) Short stature and diabetic nephropathy. B M J 310: 296-297

27. E shøj O, Vaag A, Feldt R asmussen B, B orch Johnsen K, $\mathrm{B}$ eck $\mathrm{Nielsen} \mathrm{H}$ (1995) $\mathrm{No}$ evidence of low birth weight as a risk factor for diabetic nephropathy in type I diabetic patients. D iabetologia 38: A 222 (A bstract) 